\title{
Candida/Candida biofilms. First description of dual- species Candida albicans/C. rugosa biofilm
}

\author{
Carlos Henrique Gomes MARTINS ${ }^{a, 1}$, Regina Helena PIRES ${ }^{a, b, *, 1}$, \\ Aline Oliveira CUNHA ${ }^{a}$, Cristiane Aparecida Martins PEREIRA ${ }^{a}$, \\ Junya de Lacorte SINGULANI ${ }^{b}$, Fariza ABRÃO ${ }^{a}$, Thais de MORAES ${ }^{a}$, \\ Maria José Soares MENDES-GIANNINI ${ }^{b}$
}

\author{
${ }^{a}$ Laboratorio de Pesquisa em Microbiologia Aplicada, Universidade de Franca, UNIRAN, Av. Dr. Armando Salles de \\ Oliveira, 201, Pq. Universitário, Franca, SP 14404-600, Brazil \\ bUniversidade Estadual Paulista "Júlio de Mesquita Filho", Faculdade de Ciências Farmacêuticas, UNESP, Rodovia \\ Ararquara-Jaú, km 1, Araraquara, SP 14.902-801, Brazil
}

\section{A R T I C L E I N F O}

\section{Article history:}

Received 23 July 2015

Received in revised form

19 January 2016

Accepted 20 January 2016

Available online 4 February 2016

Corresponding Editor:

Nicholas P. Money

\section{Keywords:}

Candida rugosa

Dual-species biofilms

Fungal biofilms

Oral colonization

Prostheses-related infections

\begin{abstract}
A B S T R A C T
Denture liners have physical properties that favour plaque accumulation and colonization by Candida species, irritating oral tissues and causing denture stomatitis. To isolate and determine the incidence of oral Candida species in dental prostheses, oral swabs were collected from the dental prostheses of 66 patients. All the strains were screened for their ability to form biofilms; both monospecies and dual-species combinations were tested. Candida albicans (63\%) was the most frequently isolated microorganism; Candida tropicalis (14\%), Candida glabrata (13\%), Candida rugosa (5\%), Candida parapsilosis (3\%), and Candida krusei (2 \%) were also detected. The XTT assay showed that C. albicans SC5314 possessed a biofilm-forming ability significantly higher $(p<0.001)$ than non-albicans Candida strains, after $6 \mathrm{~h} 37^{\circ} \mathrm{C}$. The total C. albicans CFU from a dual-species biofilm was less than the total CFU of a monospecies C. albicans biofilm. In contrast to the profuse hyphae verified in monospecies C. albicans biofilms, micrographies showed that the C. albicans/non-albicans Candida biofilms consisted of sparse yeast forms and profuse budding yeast cells that generated a network. These results suggested that $C$. albicans and the tested Candida species could co-exist in biofilms displaying apparent antagonism. The study provide the first description of C. albicans/C. rugosa mixed biofilm.
\end{abstract}

( 2016 The British Mycological Society. Published by Elsevier Ltd. All rights reserved.

\section{Introduction}

Candida species inhabit the human oral cavity. Candida albicans is the species that is predominantly associated with mucosal and systemic fungal infections elicited by yeasts (Miceli et al.
2011). Nevertheless non-albicans Candida species have arisen a major opportunistic pathogens. Candida glabrata, Candida parapsilosis, Candida tropicalis, and Candida krusei have been frequently isolated from the oral cavity and are often related to biofilm formation on the surface of medical devices and

\footnotetext{
* Corresponding author. Tel.: +55 16991275654.

E-mail addresses: regina.pires@unifran.edu.br, rehepi@gmail.com (R. H. Pires).

${ }^{1}$ Authors contributing equally to this article.

http://dx.doi.org/10.1016/j.funbio.2016.01.013

1878-6146/@ 2016 The British Mycological Society. Published by Elsevier Ltd. All rights reserved.
} 
tissues (Pires et al. 2002; Pires-Gonçalves et al. 2007; Zahir \& Himratul-Aznita 2013).

Biofilms constitute a structured community of microbial cells enveloped in a self-produced polymeric matrix consisting of extracellular DNA, carbohydrates, proteins, hexosamine, phosphorus, and uronic acid adhered to an inert or living surface (Flemming \& Wingender 2010). Biofilm cells inherently have limited exposure to immunological defense and antimicrobial drugs, which could account for the emergence of resistant microorganisms (Lewis 2012). Slow growth, altered cell metabolism regulation due to nutrient limitation and stress conditions, and cell density are other suggested mechanisms of biofilm resistance (Seneviratne et al. 2010). In addition, biofilms represent a significant predictor of mortality (Tumbarello et al. 2007, 2012; Silva et al. 2011) and species that produce biofilms have been correlated with poor outcome of infected patients (Tumbarello et al. 2012). For example, Candida cells surviving on dentures after chemical or mechanical treatment constitute a highly tolerant cell subpopulation (persistent) that restores the biofilm in the presence of nutrients and causes a relapse of chronic infection (Lewis 2012).

Furthermore, the oral cavity harbours a vast range of microbial species. The residents themselves might interact extensively while forming the biofilm structures, to carry out physiological functions and induce microbial pathogenesis (Kuramitsu et al. 2007; Thein et al. 2009; Kolenbrander et al. 2010). The residents may (i) compete for nutrients; (ii) interact synergistically to stimulate the growth or survival of one or more residents; (iii) produce antagonist compounds that inhibit the growth of another resident; (iv) neutralize a virulence factor produced by another resident; and (v) interfere in the growth-dependent signaling mechanisms of another resident (Kuramitsu et al. 2007). It is likely that resident microorganisms interact closely in this scenario, allowing a mixed-species biofilm to grow.

Most studies on polymicrobial biofilms have focused on the relationship between bacteria and Candida spp. However, Candida-Candida co-existence within biofilms has been poorly demonstrated (Kirkpatrick et al. 2000; Coco et al. 2008; Cuellar-Cruz et al. 2012). Thus, this study aimed to examine the frequency of Candida spp. on prostheses from denture wearers and to assess the formation of both monospecies and dual-species biofilms consisting of C. albicans and $C$. non-albicans strains. To our knowledge, this is the first report of mixed biofilm formation by C. albicans and Candida rugosa.

\section{Materials and methods}

\section{Sample}

Dental prostheses from 66 patients (33 males and 33 females, aged from 29 to 92 y) attending the outpatient clinics of the Dentistry School of the University of Franca, State of São Paulo, Brazil, were used in this study. All the subjects provided informed consent according to the protocols approved by the Human Subjects Committee of the

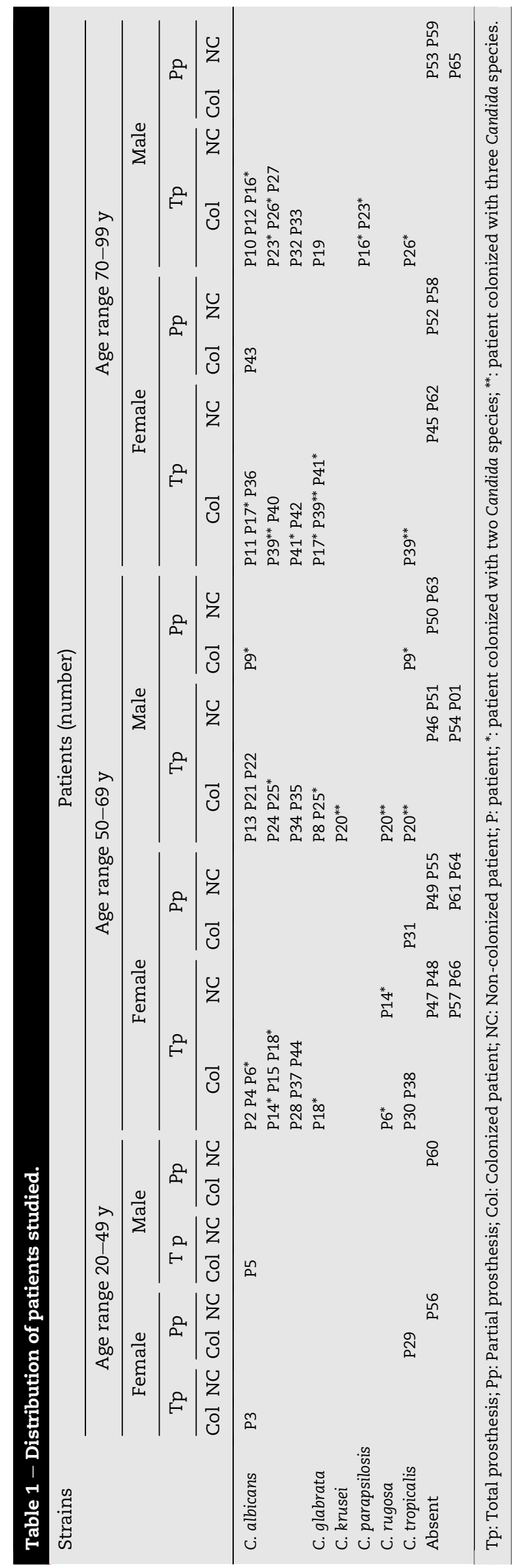


University of Franca. The patients generally self-reported good general health without severe medical or psychological conditions.

\section{Yeast isolates}

Sample collection was conducted mid morning, at least $2 \mathrm{~h}$ after eating, drinking, or postdorm hygiene procedures. A sterile swab was rubbed in the fitting surface of the dental prostheses and deposited in a tube containing Stuart medium for transport. The swabs were then inoculated on CHROMagar Candida ${ }^{\mathrm{TM}}$ medium (Becton Dickinson, Sparks, $\mathrm{MD}$ ) and incubated at $37^{\circ} \mathrm{C}$ for $48 \mathrm{~h}$. Following the manufacturer's instructions, the API ID $32 \mathrm{C}^{\mathrm{TM}}$ (bio-Merieux, Marcyl'Etoile, France) and Vitek Yeast Biochemical Card ${ }^{\mathrm{TM}}$ (bio-Merieux, Marcy-l'Etoile, France) identified the Candida species. Candida albicans was confirmed by germ tube and chlamydospore formation on cornmeal agar (Difco, Detroit, Mich, USA) $0.33 \%$ Tween 80. Reference strains of C. albicans (ATCC 90028), Candida glabrata (ATCC 2001), Candida parapsilosis (ATCC 22019), Candida krusei (ATCC 34135), Candida rugosa (ATCC 10571), Candida tropicalis (ATCC 13803) from the American Type Culture Collection (ATCC), and C. albicans SC5314 were also included.

\section{Biofilm formation}

Each Candida strain or each isolate of non-albicans Candida was co-incubated with Candida albicans SC5314 on a polystyrene surface following the protocol described by Ramage et al. (2001). Briefly, the Candida overnight culture, grown in yeast-peptone-glucose (YPG) broth [1 \% (w/v) yeast extract, $2 \%(\mathrm{w} / \mathrm{v})$ peptone, and $2 \%(\mathrm{w} / \mathrm{v})$ glucose], was diluted to $10^{6}$ cells $\mathrm{mL}^{-1}$ in RPMI 1640 medium supplemented with L-glutamine, buffered with morpholinepropanesulfonic acid (MOPS - Sigma, St. Louis, MO) at 0.165 M, pH 7.0, and added to glucose at $0.9 \%$. A total of $100 \mu \mathrm{L}$ (individually) or $50 \mu \mathrm{L}$ (for each strain, in case of dual-species biofilm) of the Candida suspension was added to the wells of a 96-well microtitre plate (Corning Inc., Corning, NY, USA). Biofilm formation was quantified at 6,12 , 18,24 , and $48 \mathrm{~h}$ at $37^{\circ} \mathrm{C}$. After incubation, the medium in the wells was removed and washed three times with sterile phosphate buffer solution (PBS). Candida albicans SC5314 was used as the control strain in all the experiments. All non-albicans Candida isolates found co-existing with C. albicans on dental prostheses were used for dual-species biofilm analysis. All isolates were assessed in quadruplicate and repeated at least three times.

\section{Biofilm quantification}

For the assessment of metabolic activity, $100 \mu \mathrm{L}$ of the XTT solution [XTT (0.5 mg mL $\mathrm{mL}^{-1}$ in PBS), menadione $(0.1 \mathrm{mM}$ in acetone)] was added to each well of the microtitre plates. After incubation at $37{ }^{\circ} \mathrm{C}$ for $5 \mathrm{~h}, 75 \mu \mathrm{L}$ of the solution was transferred to a new well of a 96-well plate, and XTT-formazan was determined at $490 \mathrm{~nm}$. In addition, aliquots $(100 \mu \mathrm{L})$ of scrapped biofilm were sonicated, serially diluted in PBS (1 mL), plated onto CHROMagar Candida ${ }^{\mathrm{TM}}$ medium, and incubated at $37^{\circ} \mathrm{C}$ for $48 \mathrm{~h}$. Colony-forming units (CFUs) of each

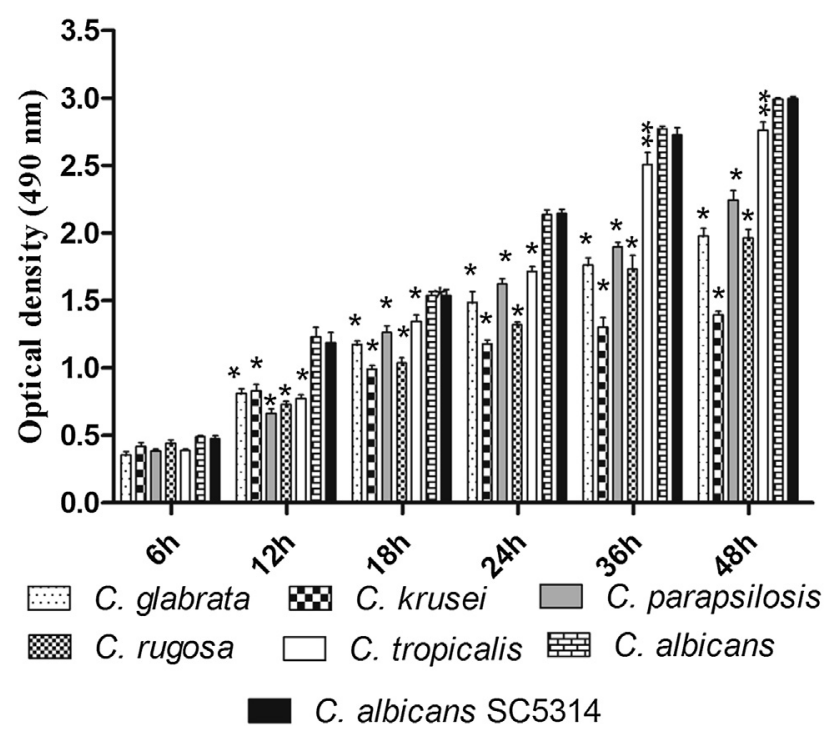

Fig 1 - Biofilm formation of Candida monospecies on microtitre plates. Biofilm viability was quantified by the XTT assay. At each time point of biofilm maturation, the optical density of Candida monospecies biofilms was compared with the optical density of C. albicans SC5314 (black columns, ${ }^{*} p<0.001 ;{ }^{* *} p<0.01$ ) by ANOVA. Data are the means \pm SD of experiments performed in quadruplicate and repeated three times.

Candida species were determined. All the isolates were assessed in quadruplicate, and the assays were repeated at least three times. The readings for the isolates of each Candida species or each Candida dual-species were averaged together, which provided the reading for the species or the pair. The

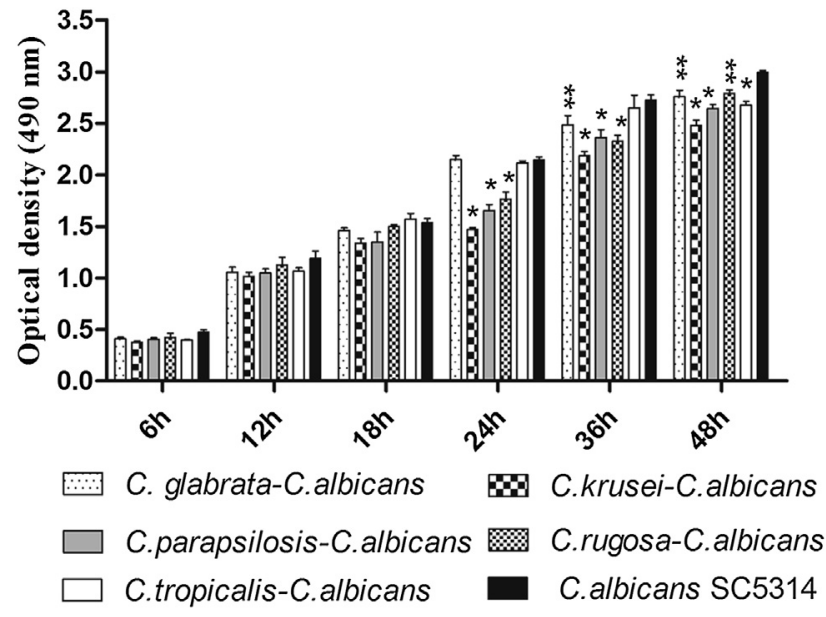

Fig 2 - Biofilm formation of Candida dual-species on microtitre plates. Biofilm viability was quantified by the XTT assay. At each time point of biofilm maturation, the optical density of mixed biofilms were compared with the optical density of C. albicans SC5314 (black columns, ${ }^{*} p<0.001$; $\left.{ }^{* *} p<0.05\right)$ by ANOVA. Data are the means \pm SD of experiments performed in quadruplicate and repeated three times. 
optical densities (ODs) of the Candida species that formed a biofilm were statistically compared with the ODs of a Candida albicans SC5314 biofilm produced in each time point. Strains with maximal OD at $6 \mathrm{~h}$ lower than or equal to 0.120 (three standard deviations (0.023) above the mean OD (0.050) of a clean tissue culture plate) were not considered to form a biofilm.

\section{Scanning electron microscopy (SEM)}

SEM imaging employed the best biofilm-forming strains of each Candida species shown in XTT assay after $48 \mathrm{~h}$. Monospecies or dual-species biofilms were formed on sterile polyvinyl chloride (PVC) disks within 24-well microtitre plates (Corning). The disks were then removed, washed with potassium phosphate buffer $0.1 \mathrm{M}, \mathrm{pH} 7.2-7.4$, and placed in a fixative [4\% formaldehyde (v/v), $1 \%$ glutaraldehyde (v/v) in potassium phosphate buffer $0.1 \mathrm{M}$ ] solution overnight. The samples were rinsed twice for $3 \mathrm{~min}$ in potassium phosphate buffer $0.1 \mathrm{M}$, post-fixed with $\mathrm{OsO}_{4}$ at $1 \%(\mathrm{w} / \mathrm{v})$ for $1 \mathrm{~h}$, dehydrated with the aid of an ethanol gradient, critical-point dried in $\mathrm{CO}_{2}$ (Critical Point 264 Dryer, model CPD-030, Balzers, Oberkochen, Germany), and gold-coated by sputtering (Denton Vacuum, model Desk II, Freehold, NJ, USA). After this process, samples were observed under a scanning electron microscope (JEOL, model JSM 5410, Japan) operating in the high vacuum mode, at $15 \mathrm{kV}$. Experiments were performed in quadruplicate and repeated at least three times.

\section{Statistic analysis}

Data were analyzed using parametric analysis of variance (ANOVA) followed by a post-hoc Bonferroni test. Graph Pad Prisma 5 (La Jolla CA, USA) was employed. All the data are reported as the means \pm the standard deviation. Significance was set at $p<0.05$.

\section{Results and discussion}

Forty-four (66 \%) patients had their dental prostheses colonized with Candida species. Candida isolates were present in dental prostheses from both females $(n=23 ; 35 \%)$ and males ( $\mathrm{n}=21 ; 32 \%$ ). As depicted in Table 1 , the age range 70-99 y (50\%) showed the highest prevalence of colonization, followed by the range 50-69 y (42\%). Of the 66 studied individuals, 55 (83\%) used complete acrylic dentures; 11 (17\%) were removable partial prostheses. Most of the elderly individuals had been using the prostheses up to $10-20$ y (39\%), followed by 6-10 y (32\%). Increased age of dental prostheses leads to wear of the material increasing porosity, roughness, grooves, and cracks, which create a niche for microbial colonization/adhesion (Fanello et al. 2006). In addition, predisposing factors associated with patients included advanced age associated with decline in the immune defense or systemic diseases and socioeconomic status (Shulman et al. 2005; Filoche et al. 2010).

The identified species corresponded to a total of 56 yeast isolates that included Candida albicans (35; $63 \%)$, Candida tropicalis (8; $14 \%)$, Candida glabrata $(7 ; 13 \%)$, Candida rugosa $(3 ; 5 \%)$,
Candida parapsilosis (2; $3 \%$ ), and Candida krusei (1; $2 \%$ ) (Table 1). In agreement with the findings of other authors (Zaremba et al. 2006; Loster et al. 2012; Pereira et al. 2013), the majority of the yeast isolates verified in the swabs corresponded to $C$. albicans (63\%), often recovered in association with other yeasts (Table 1).

Twelve (27\%) of the 44 positive cultures contained mixed Candida species. The most usual Candida dual-species consisted of C. albicans and C. glabrata (Table 1), detected in $5 \%$ of the samples, in agreement with Cavaleiro et al. (2013). Interestingly, in a recently published study (Mario et al. 2012), C. glabrata emerged as the fifth most commonly isolated Candida species in Brazil. Other researchers have also reported on cultures containing mixed Candida species (Torres et al. 2003; AltEpping et al. 2012). The emergence of yeasts other than C. albicans and of mixed infections has suggested that the epidemiology of Candida infections is changing. Consequently, these infections may require higher doses of antifungal agents and may predispose patients to recurrent candidiasis, mainly because Candida species such as C. glabrata and C. krusei are becoming resistant to currently available antifungal treatments (Thein et al. 2009; Guinea 2014).

Candida strains grown on polystyrene formed biofilms. A total of 48 strains generated biofilms. The XTT assay showed that the clinical and ATCC strains of C. albicans (Fig 1) did not differ significantly in terms of biofilm production. After $6 \mathrm{~h}$ at $37^{\circ} \mathrm{C}, \mathrm{C}$. albicans SC5314 presented significantly higher $(p<0.001)$ biofilm-forming ability than non-albicans Candida strains (Fig 1). In the case of C. tropicalis, at $36 \mathrm{~h}$ and $48 \mathrm{~h}$, the difference was smaller $(p<0.01)$.

Compared with the monospecies C. albicans SC5314 biofilms, the dual-species C. albicans/non-albicans Candida biofilms had significantly different metabolic activity from $18 \mathrm{~h}$ (Fig 2). Candida albicans/C. glabrata biofilms presented different metabolic activity after $36-48 \mathrm{~h}(p<0.05)$. For C. albicans/C. krusei and C. albicans/C. parapsilosis biofilms, different metabolic activities were observed from $24 \mathrm{~h}$ to $48 \mathrm{~h}(p<0.001)$. Candida albicans/C. rugosa co-cultures have different metabolic activity from $24 \mathrm{~h}$ to $36 \mathrm{~h}(p<0.001)$ and from $48 \mathrm{~h}(p<0.05)$. The dual-species C. albicans/C. tropicalis biofilms only presented significantly different metabolic activity after $48 \mathrm{~h}$ of incubation at $37^{\circ} \mathrm{C}(p<0.001)$. Overall, analysis of these biofilms showed that $C$. tropicalis in monoculture or co-cultured with C. albicans formed denser biofilms (Figs 1 and 2). In agreement with previous studies, C. tropicalis was more successful at forming biofilms in comparison with other Candida species (Silva et al. 2011; Marcos-Zambrano et al. 2014). In addition, the biofilm-forming ability and structure are microbial strain- and species-dependent (Silva et al. 2011).

Biofilm formation is an important virulence factor in numerous Candida species (Tumbarello et al. 2007). Katragkou et al. (2010) demonstrated that reduced cytokine production occurs in a biofilm-phagocyte co-culture as compared with a mixture of planktonic cells and phagocytes (phagocytes become entrapped within the structured network of cells and matrix, so they cannot internalize cells within the biofilms). Furthermore, in edentulous patients, prostheses can cause multiple alterations in the oral environment including changes in saliva and in phosphate, calcium, and protein deposits on the acrylic surfaces that are in contact with the 

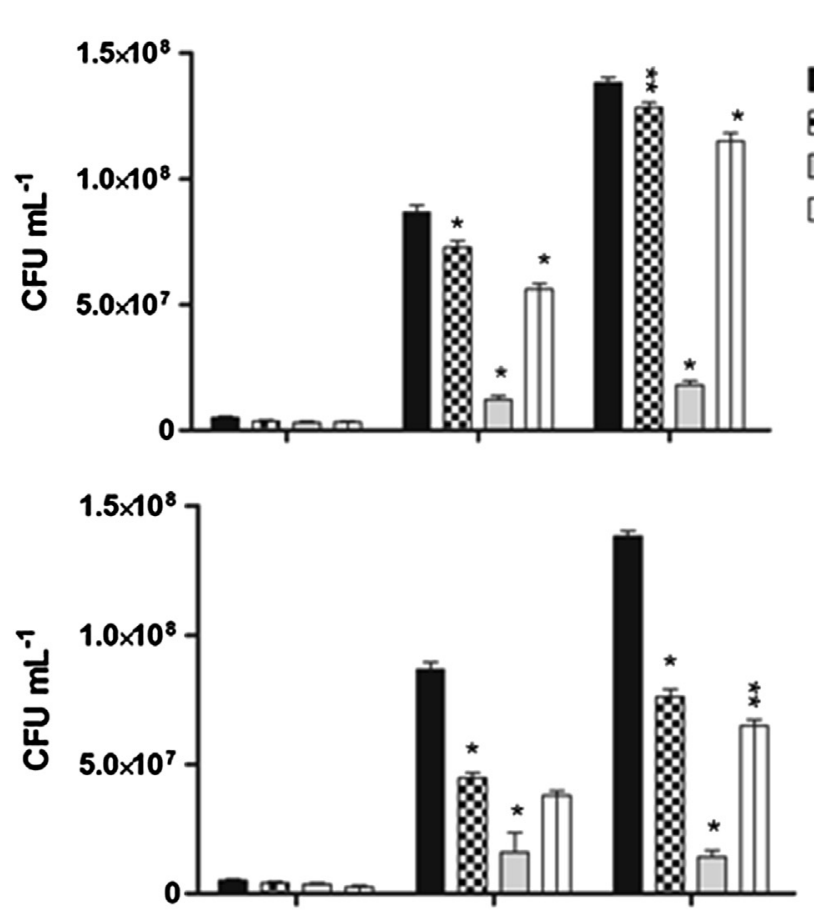

C. albicans SC5314

$\$$ C. glabrata

C. albicans mixed

m C. glabrata mixed

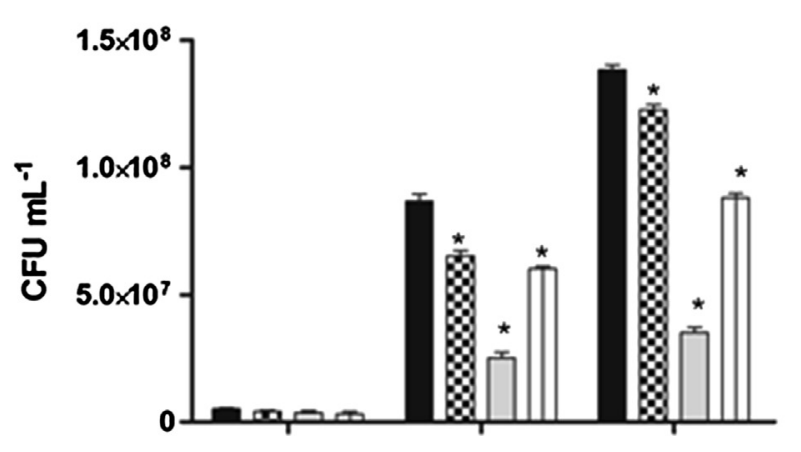

- C. albicans SC5314

8 C. krusei

C. albicans mixed

UII C. krusei mixed

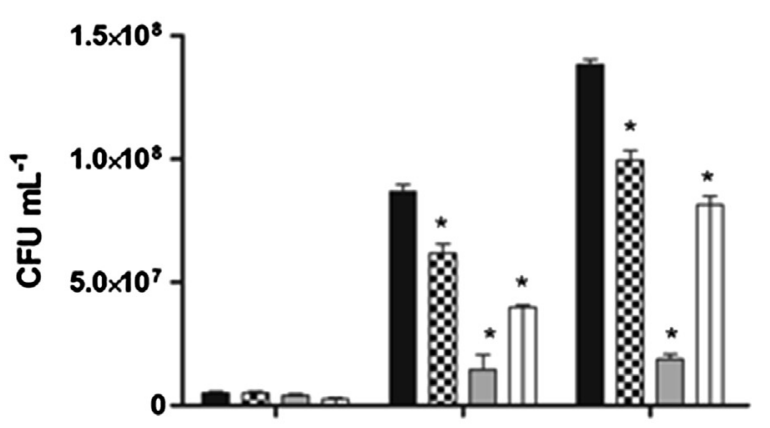

C. albicans SC5314

$\$$ C. parapsilosis

C. albicans mixed

띠 C. parapsilosis mixed

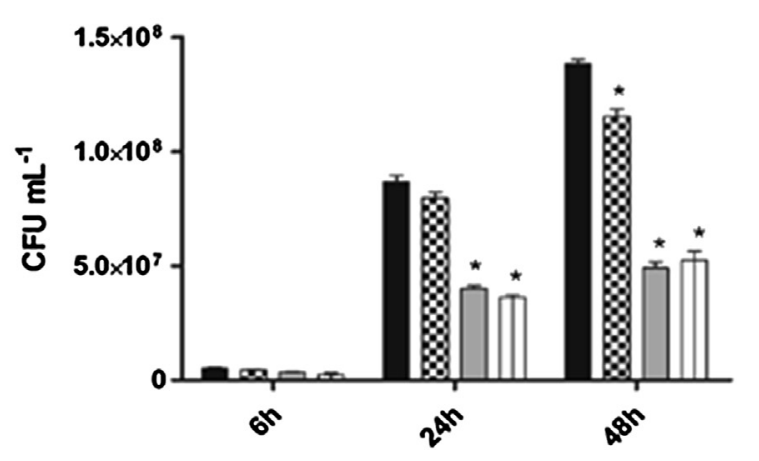

C. albicans SC5314

$\$$ C. rugosa

C. albicans mixed

C. rugosa mixed

\section{C. albicans SC5314}

$\infty$ C. tropicalis

C.albicans mixed

un C. tropicalis mixed

Fig 3 - Total cell numbers (CFU mL ${ }^{-1}$ ) from monospecies and dual-species biofilms of C. albicans SC5314 and non-albicans Candida strains. The results were performed on 6, 24, and $48 \mathrm{~h}$ at $37^{\circ} \mathrm{C}$. When compared to C. albicans SC5314 at $24 \mathrm{~h}$ of 

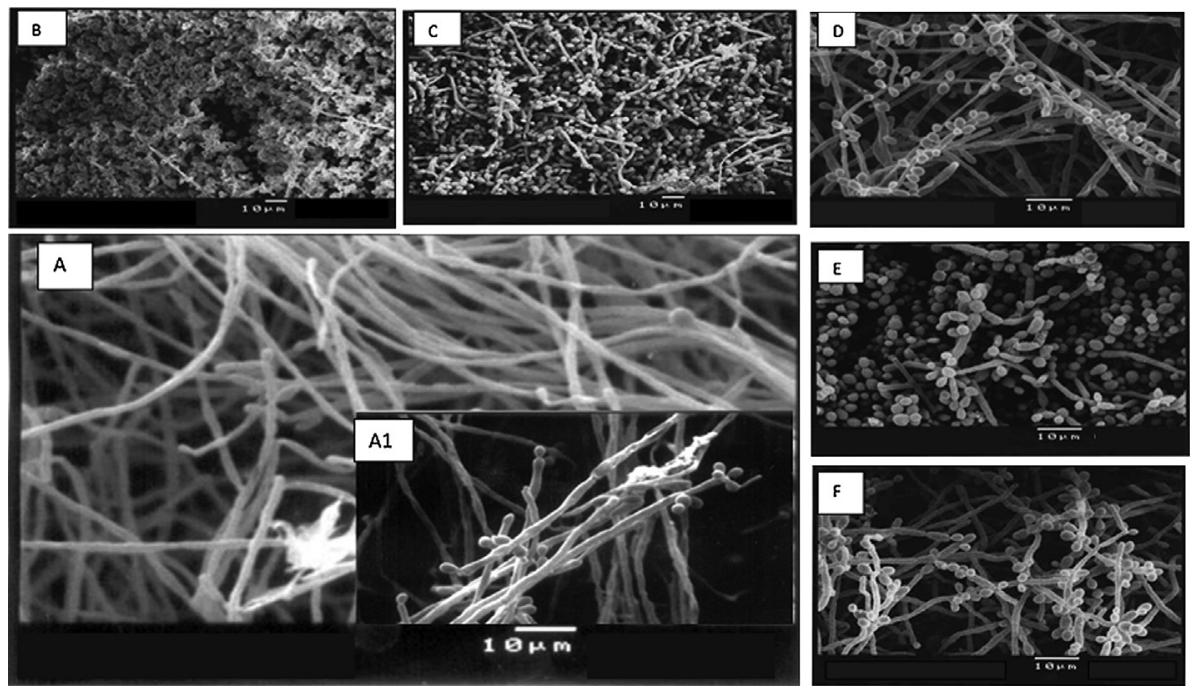

Fig 4 - Representative scanning electron microscopy images of a dual-species Candida biofilm as compared with the monospecies C. albicans SC5314 biofilm. Note that the $C$. albicans biofilms $\left(A / A_{1}\right)$ consisted of a dense layer of hyphae whereas in dual-species Candida biofilms [(B) - C. albicans plus C. glabrata (P17); (C) - C. albicans plus C. tropicalis (P38); (D) - C. albicans plus C. krusei (P20); (E) - C. albicans plus C. parapsilosis (P16); (F) - C. albicans plus C. rugosa (P14)] single cells (blastospores) predominated.

epithelium, competition between microorganisms for adherence, decreased $\mathrm{pH}$, and increased potential for oxide reduction. As a result, fungal species demand rapid osmotic adaptation, oxidative stress response, and metabolic changes that promote biofilm formation (Sanchez-Vargas et al. 2013).

Fig 3 represents the mean values of $\mathrm{CFU} \mathrm{mL} \mathrm{m}^{-1}$ obtained for monospecies and dual-species biofilms of C. albicans and Candida non-albicans produced at $6 \mathrm{~h}$ (early biofilms), $24 \mathrm{~h}$ (intermediate biofilms), and $48 \mathrm{~h}$ at $37{ }^{\circ} \mathrm{C}$ (mature biofilms). Compared to CFU $\mathrm{mL}^{-1}$ of C. albicans SC5314 no difference was observed to all non-albicans Candida biofilms at $6 \mathrm{~h}$ incubation time. At $24 \mathrm{~h}, \mathrm{CFU} \mathrm{mL} \mathrm{m}^{-1}$ from C. glabrata, C. krusei and C. rugosa differed significantly from the reference strains $(p<0.001)$, although for $C$. parapsilosis this difference was smaller $(p<0.05)$; no difference was observed with $C$. tropicalis (Fig 3). At $48 \mathrm{~h}$ incubation, all non-albicans Candida biofilms differed significantly from CFU $\mathrm{mL}^{-1}$ C. albicans SC5314 ( $p<0.001$; C. glabrata, $p<0.05$ ) (Fig 3). In all the co-cultured biofilms, the total CFU $\mathrm{mL}^{-1}$ of each organism was significantly different from the total $\mathrm{CFU} \mathrm{mL} \mathrm{m}^{-1}$ of the corresponding monospecies Candida biofilms over $24 \mathrm{~h}-48 \mathrm{~h}$ of biofilm generation ( $p<0.05 ; p<0.001)$. In addition, the non-albicans Candida species dominated in all the co-culture biofilms, although the initial concentrations of the two species in the inocula were the same. These results were consistent with the results published by El-Azizi et al. (2004), who reported that addition of $C$. albicans to preformed C. krusei, Candida lipolytica, or Candida guilliermondii biofilms and the co-incubation of C. albicans with other Candida species like C. krusei, C. glabrata, C. lipolytica, C. guilliermondii, or C. parapsilosis diminishes the number of C. albicans cells within the resulting mixed biofilms. Competitive inhibition may occur even in the initial step of adhesion onto a substrate during dual-species Candida biofilm development (Thein et al. 2009).

Cell numbers from biofilms confirmed visual differences in the biofilm organism constitution. SEM analysis of mixedspecies Candida biofilms (Fig 4B-F) displayed a low abundance of hyphae and profuse distribution of blastospores as compared with the reference monospecies C. albicans biofilm (Fig 4A and $\mathrm{A}_{1}$ ). In agreement with Kirkpatrick et al. (2000) and Thein et al. (2009), interaction of the two Candida species seemed to suppress each other's growth, possibly because they competed for nutrients and/or one of the species generated toxic metabolites. Recently, Wright et al. (2013), demonstrated that the transition from the planktonic growth mode to a biofilm community prompts major transcriptional and proteomic changes. These modifications occur in response to sensing of diffusible signals, such as autoinducer molecules, and to contact with host tissues or other microbial cells. In addition, the presence of $C$. glabrata seemed to reduce hyphal development by C. albicans in previous studies (Agwu et al. 2012; Tournu \& Van Dijck 2012).

The present study has been the first to report on the in vitro formation of a mixed biofilm containing C. albicans and $C$.

maturation, the results showed a significant decrease of the number of non-albicans Candida in monospecies biofilms, except for C. tropicalis strains. At $48 \mathrm{~h}$, all non-albicans Candida monospecies biofilms present significant decrease in the CFU $\mathrm{mL}^{-1}$. In all the co-cultured biofilms, the total CFU $\mathrm{mL}^{-1}$ of each organism was significantly different from the total CFU $\mathrm{mL}^{-1}$ of the corresponding monospecies Candida biofilms over $24 \mathrm{~h}-\mathbf{4 8} \mathrm{h}$ of biofilm generation. Error bars represent the standard deviation of four replicates. ${ }^{*} p<0.001 ;{ }^{* *} p<0.05$. 

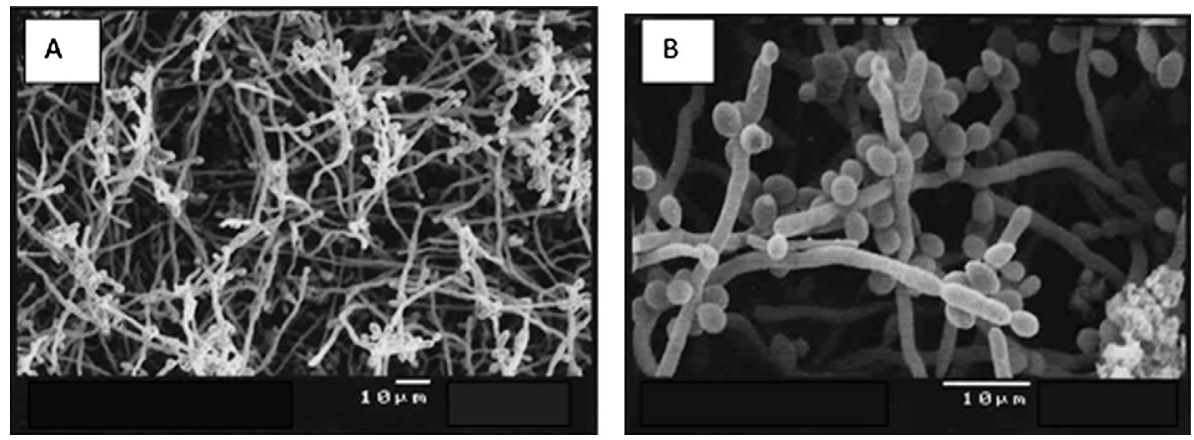

Fig 5 - Representative electron micrographs of dual-species C. albicans/C. rugosa biofilms. Note that the biofilms display blastospore, hyphae, and pseudohyphae elements. Magnification: A 750×; B 2000×.

rugosa strains (Fig 5). Infections caused by less common Candida species have increased in past years (Colombo et al. 2003; Pfaller et al. 2010; Mohammadi et al. 2015), and C. rugosa has been recognized as an emerging fungal pathogen (Pfaller et al. 2010; Mohammadi et al. 2015; Ghosh et al. 2015). This species has been found in Latin America, particularly in Brazil (Colombo et al. 2003; Pfaller et al. 2010). Moreover, this fungus has lower susceptibility to fluconazole, amphotericin B, and echinocandins (Pfaller et al. 2010; Espinel-Ingroff et al. 2014). In agreement with Colombo et al. (2003) and Tay et al. (2011), this work obtained isolates from elderly patients, which confirmed that older individuals are at higher risk of infection with C. rugosa. Tay et al. (2011) had previously reported on the ability of $C$. rugosa isolates to form biofilms on plastic surfaces in vitro. Some authors have associated C. rugosa with catheter-related infections and resistance against therapy (Colombo et al. 2003; Espinel-Ingroff et al. 2014).

This study attested that C. albicans was the Candida species most often associated with colonization of dental prostheses. Non-albicans species like C. tropicalis, C. parapsilosis, C. glabrata, C. krusei, and C. rugosa did not emerge as single colonizers but rather in co-colonization with $C$. albicans. All the recovered non-albicans Candida species displayed monospecies biofilmforming ability and formed mixed Candida biofilms with reference strains C. albicans SC5314 in vitro. All the mixed communities apparently engaged in an antagonistic relationship because the presence of hyphae (a more invasive form of $C$. albicans) decreased as compared with monospecies C. albicans biofilms. In addition, the CFU mL ${ }^{-1}$ of C. albicans SC5314 in all the dual-species biofilms decreased significantly when compared with C. albicans monospecies biofilms. Such information could cast light on Candida species interactions in biofilm communities from dental prostheses isolates and lead to novel approaches for the control of such biofilms.

\section{Acknowledgments}

The work conducted at Faculdade de Ciências Farmacêuticas de Araraquara, FCFAr - UNESP was supported by grants from Fundação de Amparo à Pesquisa do Estado de São Paulo (FAPESP), fellowship \# 2011/12734-3.

\section{R E F E R E N C E S}

Agwu E, Ihongbe JC, McManus BA, Moran GP, Coleman DC, Sullivan DJ, 2012. Distribution of yeast species associated with oral lesions in HIV-infected patients in Southwest Uganda. Medical Mycology 50: 276-280.

Alt-Epping B, Nejad RK, Jung K, Gross U, Nauck F, 2012. Symptoms of the oral cavity and their association with local microbiological and clinical findings - a prospective survey in palliative care. Support Care Cancer 20: 531-537.

Cavaleiro I, Proenca L, Felix S, Salema-Oom M, 2013. Prevalence of yeast other than Candida albicans in denture wearers. Journal of Prosthodontics 22: 351-357.

Coco BJ, Bagg J, Cross LJ, Jose A, Cross J, Ramage G, 2008. Mixed Candida albicans and Candida glabrata populations associated with the pathogenesis of denture stomatitis. Oral Microbiology and Immunology 23: 377-383.

Colombo AL, Melo AS, Crespo Rosas RF, Salomão R, Briones M, Hollis RJ, Messer SA, Pfaller MA, 2003. Outbreak of Candida rugosa candidemia: an emerging pathogen that may be refractory to amphotericin B therapy. Diagnostic Microbiology and Infectious Disease 46: 253-257.

Cuellar-Cruz M, Lopez-Romero E, Villagomez-Castro JC, RuizBaca E, 2012. Candida species: new insights into biofilm formation. Future Microbiology 7: 755-771.

El-Azizi MA, Starks SE, Khardori N, 2004. Interactions of Candida albicans with other Candida spp. and bacteria in the biofilms. Journal of Applied Microbiology 96: 1067-1073.

Espinel-Ingroff A, Pfaller MA, Bustamante B, Canton E, Fothergill A, Fuller J, Gonzalez GM, Lass-Flörl C, Lockhart SR, Martin-Mazuelos E, Meis JF, Melhem MS, Ostrosky-Zeichner L, Pelaez T, Szeszs MW, St-Germain G, Bonfietti LX, Guarro J, Turnidge J, 2014. Multilaboratory study of epidemiological cutoff values for detection of resistance in eight Candida species to fluconazole, posaconazole, and voriconazole. Antimicrobial Agents Chemotherapy 58: 2006-2012.

Fanello S, Bouchara JP, Sauteron M, Delbos V, Parot E, MarotLeblond A, Moalic E, Le Flohice AM, Brangerd B, 2006. Predictive value of oral colonization by Candida yeasts for the onset of a nosocomial infection in elderly hospitalized patients. Journal of Medical Microbiology 55: 223-228.

Filoche S, Wong L, Sissons CH, 2010. Oral biofilms: emerging concepts in microbial ecology. Journal of Dental Research 89 : 8-18.

Flemming HC, Wingender J, 2010. The biofilm matrix. Nature Reviews Microbiology 8: 623-633. 
Ghosh AK, Paul S, Sood P, Rudramurthy SM, Rajbanshi A, Jillwin TJ, Chakrabarti A, 2015. Matrix-assisted laser desorption ionization time-of-flight mass spectrometry for the rapid identification of yeasts causing bloodstream infections. Clinical Microbiology and Infection 21: 372-378.

Guinea J, 2014. Global trends in the distribution of Candida species causing candidemia. Clinical Microbiology and Infection 20 (Suppl. 6): 5-10.

Katragkou A, Kruhlak MJ, Simitsopoulou M, Chatzimoschou A, Taparkou A, Cotten CJ, Paliogianni F, Diza-Mataftsi E, Tsantali C, Walsh TJ, Roilides E, 2010. Interactions between human phagocytes and Candida albicans biofilms alone and in combination with antifungal agents. The Journal of Infectious Diseases 201: 1941-1949.

Kirkpatrick WR, Lopez-Ribot JL, McAtee RK, Patterson TF, 2000. Growth competition between Candida dubliniensis and Candida albicans under broth and biofilm growing conditions. Journal Clinical Microbiology 38: 902-904.

Kolenbrander PE, Palmer Jr RJ, Periasamy S, Jakubovics NS, 2010. Oral multispecies biofilm development and the key role of cell-cell distance. Nature Reviews Microbiology 8: 471-480.

Kuramitsu HK, He X, Lux R, Anderson MH, Shi W, 2007. Interspecies interactions within oral microbial communities. Microbioliology and Molecular Biology Reviews 71: 653-670.

Lewis K, 2012. Persister cells: molecular mechanisms related to antibiotic tolerance. Handbook of Experimental Pharmacology 211: 121-133.

Loster BW, Loster J, Wieczorek A, Ryniewicz W, 2012. Mycological analysis of the oral cavity of patients using acrylic removable dentures. Gastroenterology Research and Practice 2012: 951572.

Marcos-Zambrano LJ, Escribano P, Bouza E, Guinea J, 2014. Production of biofilm by Candida and non-Candida spp. isolates causing fungemia: comparison of biomass production and metabolic activity and development of cut-off points. International Journal of Medical Microbiology 304: 1192-1198.

Mario DA, Denardi LB, Bandeira LA, Antunes MS, Santurio JM, Severo LC, Alves SH, 2012. The activity of echinocandins, amphotericin B and voriconazole against fluconazolesusceptible and fluconazole-resistant Brazilian Candida glabrata isolates. Memorias do Instituto Oswaldo Cruz 107: 433-436.

Miceli MH, Diaz JA, Lee AS, 2011. Emerging opportunistic yeast infections. The Lancet Infectious Diseases 11: 142-151.

Mohammadi R, Badiee P, Badali H, Abastabar M, Safa AH, Hadipour M, Yazdani H, Heshmat F, 2015. Use of restriction fragment length polymorphism to identify Candida species, related to onychomycosis. Advanced Biomedical Research 4: 95.

Pereira CA, Toledo BC, Santos CT, Pereira Costa AC, BackBrito GN, Kaminagakura E, Jorge AO, 2013. Opportunistic microorganisms in individuals with lesions of denture stomatitis. Diagnostic Microbiology and Infectious Disease 76: 419-424.

Pfaller MA, Diekema DJ, Gibbs DL, Newell VA, Ellis D, Tullio V, Rodloff A, Fu W, Ling TAGlobal Antifungal Surveillance Group, 2010. Results from the ARTEMIS DISK Global Antifungal Surveillance Study, 1997 to 2007: a 10.5-year analysis of susceptibilities of Candida species to fluconazole and voriconazole as determined by CLSI standardized disk diffusion. Journal of Clinical Microbiology 48: 1366-1377.

Pires FR, Santos EB, Bonan PR, De Almeida OP, Lopes MA, 2002. Denture stomatitis and salivary Candida in Brazilian edentulous patients. Journal of Oral Rehabilitation 29: 1115-1119.
Pires-Gonçalves RH, Miranda ET, Baeza LC, Matsumoto MT, Zaia JE, Mendes-Giannini MJ, 2007. Genetic relatedness of commensal strains of Candida albicans carried in the oral cavity of patients' dental prosthesis users in Brazil. Mycopathologia 2007: 255-263.

Ramage G, Vande Walle K, Wickes BL, Lopez-Ribot JL, 2001. Standardized method for in vitro antifungal susceptibility testing of Candida albicans biofilms. Antimicrobial Agents Chemotherapy 45: 2475-2479.

Sanchez-Vargas LO, Estrada-Barraza D, Pozos-Guillen AJ, RivasCaceres R, 2013. Biofilm formation by oral clinical isolates of Candida species. Archives of Oral Biology 58: 1318-1326.

Seneviratne CJ, Wang Y, Jin L, Abiko Y, Samaranayake LP, 2010. Proteomics of drug resistance in Candida glabrata biofilms. Proteomics 10: 1444-1454.

Shulman JD, Rivera-Hidalgo F, Beach MM, 2005. Risk factors associated with denture stomatitis in the United States. Journal of Oral Pathology \& Medicine 34: 340-346.

Silva S, Negri M, Henriques M, Oliveira R, Williams DW, Azeredo J, 2011. Adherence and biofilm formation of non-Candida albicans Candida species. Trends in Microbiology 19: 241-247.

Tay ST, Tan HW, Na SL, Lim SL, 2011. Phenotypic and genotypic characterization of two closely related subgroups of Candida rugosa in clinical specimens. Journal of Medical Microbiology 60: 1591-1597.

Thein ZM, Seneviratne CJ, Samaranayake YH, Samaranayake LP, 2009. Community lifestyle of Candida in mixed biofilms: a mini review. Mycoses 52: 467-475.

Torres SR, Peixoto CB, Caldas DM, Silva EB, Magalhães FA, Uzeda M, Nucci M, 2003. Clinical aspects of Candida species carriage in saliva of xerotomic subjects. Medical Mycology 41: 411-415.

Tournu H, Van Dijck P, 2012. Candida biofilms and the host: models and new concepts for eradication. International Journal of Microbiology 2012: 845352.

Tumbarello M, Fiori B, Trecarichi EM, Posteraro P, Losito AR, De Luca A, Sanguinetti M, Fadda G, Cauda R, Posteraro B, 2012. Risk factors and outcomes of candidemia caused by biofilmforming isolates in a tertiary care hospital. PLoS One 7: e33705.

Tumbarello M, Posteraro B, Trecarichi EM, Fiori B, Rossi M, Porta R, de Gaetano Donati K, La Sorda M, Spanu T, Fadda G, Cauda R, Sanguinetti M, 2007. Biofilm production by Candida species and inadequate antifungal therapy as predictors of mortality for patients with candidemia. Journal of Clinical Microbiology 45: 1843-1850.

Wright CJ, Burns LH, Jack AA, Back CR, Dutton LC, Nobbs AH, Lamont RJ, Jenkinson HF, 2013. Microbial interactions in building of communities. Molecular Oral Microbiology 28: 83-101.

Zahir RA, Himratul-Aznita WH, 2013. Distribution of Candida in the oral cavity and its differentiation based on the internally transcribed spacer (ITS) regions of rDNA. Yeast 30: 13-23.

Zaremba ML, Daniluk T, Rozkiewicz D, Cylwik-Rokicka D, Kierklo A, Tokajuk G, Dabrowska E, Pawińska M, Klimiuk A, Stokowska W, Abdelrazek S, 2006. Incidence rate of Candida species in the oral cavity of middle-aged and elderly subjects. Advances in Medical Sciences 51 (Suppl. 1): 233-236. 